\title{
BAMS
}

\section{High-Resolution Operational Ocean Forecast and Reanalysis System for the Indian Ocean}

\author{
P. A. Francis, A. K. Jithin, J. B. Effy, A. Chatterjee, K. Chakraborty, A. Paul, \\ B. Balaji, S. S. C. Shenoi, P. Biswamoy, A. Mukherjee, P. Singh, B. Deepsankar, \\ S. Siva Reddy, P. N. Vinayachandran, M. S. Girish Kumar, T. V. S. Udaya Bhaskar, \\ M. Ravichandran, A. S. Unnikrishnan, D. Shankar, A. Prakash, S. G. Aparna, \\ R. Harikumar, K. Kaviyazhahu, K. Suprit, R. V. Shesu, N. Kiran Kumar, \\ N. Srinivasa Rao, K. Annapurnaiah, R. Venkatesan, A. S. Rao, \\ E. N. Rajagopal, V. S. Prasad, M. D. Gupta, T. M. Balakrishnan Nair, \\ E. P. R. Rao, and B. V. Satyanarayana
}

\begin{abstract}
A good understanding of the general circulation features of the oceans, particularly of the coastal waters, and ability to predict the key oceanographic parameters with good accuracy and sufficient lead time are necessary for the safe conduct of maritime activities such as fishing, shipping, and offshore industries. Considering these requirements and buoyed by the advancements in the field of ocean modeling, data assimilation, and ocean observation networks along with the availability of the high-performance computational facility in India, Indian National Centre for Ocean Information Services has set up a "High-Resolution Operational Ocean Forecast and Reanalysis System" (HOOFS) with an aim to provide accurate ocean analysis and forecasts for the public, researchers, and other types of users like navigators and the Indian Coast Guard. Major components of HOOFS are (i) a suite of numerical ocean models configured for the Indian Ocean and the coastal waters using the Regional Ocean Modeling System (ROMS) for forecasting physical and biogeochemical state of the ocean and (ii) the data assimilation based on local ensemble transform Kalman filter that assimilates in situ and satellite observations in ROMS. Apart from the routine forecasts of key oceanographic parameters, a few important applications such as (i) Potential Fishing Zone forecasting system and (ii) Search and Rescue Aid Tool are also developed as part of the HOOFS project. The architecture of HOOFS, an account of the quality of ocean analysis and forecasts produced by it and important applications developed based on HOOFS are briefly discussed in this article.
\end{abstract}

https://doi.org/10.1175/BAMS-D-19-0083.1

Corresponding author: P. A. Francis, francis@incois.gov.in

In final form 1 May 2020

(๑)2020 American Meteorological Society

For information regarding reuse of this content and general copyright information, consult the AMS Copyright Policy. 
AFFILIATIONS: Francis, Chatterjee, Chakraborty, Paul, Shenoi, Biswamoy, Mukherjee, Singh, Deepsankar, Girish Kumar, Bhaskar, Harikumar, Kaviyazhahu, Suprit, Shesu, Kiran Kumar, Srinivasa Rao, Annapurnaiah, Nair, Rama Rao, and Satyanarayana_-Indian National Centre for Ocean Information Services, Ministry of Earth Sciences, Hyderabad, India; Jithin and Effy_Indian National Centre for Ocean Information Services, Ministry of Earth Sciences, Hyderabad, and Department of Physical Oceanography and Meteorology, Andhra University, Vishakhapatnam, India; Balaji-Indian National Centre for Ocean Information Services, Ministry of Earth Sciences, Hyderabad, and Indian Institute of Tropical Meteorology, Ministry of Earth Sciences, Pune, India; Reddy_Indian National Centre for Ocean Information Services, Ministry of Earth Sciences, Hyderabad, India, and Computer, Electrical, and Mathematical Science and Engineering, King Abdullah University of Science and Technology, Thuwal, Saudi Arabia; Vinayachandran-Centre for Atmospheric and Oceanic Sciences, Indian Institute of Science, Bangalore, India; Ravichandran-National Centre for Polar and Ocean Research, Ministry of Earth Sciences, Goa, India; Unnikrishnan, Shankar, and Aparna-National Institute of Oceanography, CSIR, Goa, India; Prakash-National Institute of Oceanography, CSIR, Vishakhapatnam, India; Venkatesan-National Institute of Ocean Technology, Ministry of Earth Sciences, Chennai, India; Suryachandra Rao_-Indian Institute of Tropical Meteorology, Ministry of Earth Sciences, Pune, India; Rajagopal, Prasad, and Gupta-National Centre for Medium Range Weather Forecasting, Ministry of Earth Sciences, Noida, India

A ccurate forecasts of specific oceanographic parameters such as currents, temperature, and salinity in the surface and subsurface ocean, tides, and wind waves are essential for planning most of the maritime activities and securing the lives and livelihoods of millions of people who venture into oceans (Francis et al. 2013). The users of the operational ocean forecasts and information range from traditional fisher folks to high-tech maritime industries. Recognizing the importance of accurate predictions of oceanographic parameters, particularly for the waters around India, Ministry of Earth Sciences (MoES), Government of India, entrusted Indian National Centre for Ocean Information Services (INCOIS) to design, develop, and operate a comprehensive, very high-resolution ocean forecast and analysis/ reanalysis system. This led to the development of a High-Resolution Operational Ocean Forecast and Reanalysis System (HOOFS)-the operational ocean forecast system of India. The architecture of HOOFS, important products and applications of this system, and verification of the ocean analysis and forecasts generated by it are briefly discussed in this paper.

A good understanding on the circulation of the Indian Ocean in general, and coastal waters around India in particular, is a prerequisite for designing and developing a forecast system for the Indian Ocean. Tides, which are responsible for a substantial fraction of variability observed in currents and sea level in the coastal regions, are mixed semidiurnal in the Arabian Sea (AS) and predominantly semidiurnal in the Bay of Bengal (BoB) (Sindhu and Unnikrishnan 2013). Tidal currents over wide continental shelves in the northern BoB and off the west coast of India have comparable magnitudes and sometimes stronger than the subtidal currents, suggesting their importance in the ocean dynamics of this region (Mandal et al. 2020; Subeesh et al. 2013; Unnikrishnan et al. 1999). Though tidal currents are not prominent in the open ocean, their interactions with bottom topographic features generate internal gravity waves (internal tides), which significantly influence the vertical mixing (Nash et al. 2004; Waterhouse et al. 2014), sediment suspension (Butman et al. 2006), and biological productivity in the ocean (Pingree et al.1986, Sharples et al. 2009). Studies suggest that Chagos-Laccadive Ridge and AndamanNicobar (AN) Ridge are the two important sources of internal tides in this region and internal tides generated here propagate all over the southeastern AS and BoB, respectively (Jithin et al. 2019, 2020, 2017a; Subeesh 2019). Jithin et al. (2019) have shown that a substantial variability of the internal tides observed off the east coast of India are driven by those originating from the AN Ridge, which is located about 1,000 km away from the coast. Apart from tides, presence of coastally trapped waves (CTW) is an important feature observed along the Indian coasts, 
which causes significant variability in the currents and sea level on the continental shelf (Amol et al. 2012; Shetye and Vijith 2013). Studies have shown that the CTWs are often linked to winds blowing hundreds of kilometers away from the regions they are seen (Amol et al. 2012; N. Anup et al.2020, unpublished manuscript).

The subtidal circulation of the northern Indian Ocean is primarily driven by the monsoon winds, which have characteristic seasonal reversal. The prominent features of the upperocean circulation in the northern Indian Ocean thus reverses seasonally along the west and east coasts of India and in the open seas (Shankar et al.2002). During the summer monsoon (June to September), the West India Coastal Current (WICC) flows equatorward while the East India Coastal Current (EICC) flows poleward. The direction of WICC and EICC turn poleward and equatorward, respectively, during winter monsoon (November to January; Shetye et al. 1993, 1991, 1990). The strong monsoon currents seen to the north of the equator flow eastward during the summer monsoon and westward during the winter monsoon (Shankar et al. 2002; Shenoi et al. 1999). It may be noted that, in addition to the local surface forcing, the coastal circulation around India is highly influenced by remote forcing from the interior Bay of Bengal and the equatorial Indian Ocean (Potemra et al. 1991; Shankar et al.1996; Yu et al. 1991). The interplay between these different forcing mechanisms makes the surface and subsurface circulation along the Indian coasts highly incoherent (Amol et al. 2014; McCreary et al. 1993; Mukherjee et al. 2014; Shankar et al. 2002). Recent observations based on coastal radar data suggest that variability in the boundary currents, for instance, EICC, significantly influences the currents even at the coast (Mukhopadhyay et al. 2017).

Another important feature of both EICC and WICC is the existence of strong undercurrents beneath the strong surface flow (Amol et al. 2014; Mukherjee et al. 2014; Shetye et al. 1991). In a recent study, Francis et al. (2020) have shown that the undercurrents in the EICC are formed due to the interaction of westward-propagating mesoscale eddies with topography. It may be noted that the mesoscale eddy activity in the BoB is very strong and they play important roles in the variability of EICC and the circulation in the interior BoB (Chen et al. 2018). It has also been shown that the variability of isothermal layers in the interior Bay of Bengal is also influenced by the winds over the equatorial Indian Ocean through remote effects (Girishkumar et al. 2013). Recent studies have suggested that the AN Islands play an important 
role in the accurate simulation of subtidal circulation in the Bay of Bengal (Chatterjee et al. 2017; Mukherjee et al. 2019).

Designing forecast systems for regional waters, particularly for the coastal oceans, poses several challenges due various factors including the complex bathymetry and coastline, interaction of coastal circulation with local and remote forcing, and availability of suitable atmospheric forcing fields. Apart from these, a unique feature of Bay of Bengal is the discharge of large quantities of freshwater from the rivers like Ganga and Brahmaputra, which causes strong stratification in the upper ocean that limits the mixed layer to a few tens of meters and influencing the circulation significantly (Vinayachandran and Kurian 2007). Inclusion of river discharge data in real time in high-resolution operational forecast models still remains as a challenge. In general, the operational agencies configure a series of ocean forecast systems, nested in larger-scale forecast/analysis systems to meet the specific requirements of regional applications. A good example of such a system is a national network of operational nowcast and forecast hydrodynamic model systems designed and operated by NOAA (https://tidesandcurrents.noaa.gov/models .html). This system includes several regional-scale configurations of hydrodynamic models for the coastal waters, bays, and larger lakes in and around the United States to issue the nowcast and forecasts up to $48 \mathrm{~h}$ lead time. There are several similar high-resolution operational forecast systems for other parts of coastal waters and marginal seas in Australia, Asia, and Europe (a complete list of such systems can be found at www.godae-oceanview.org/science/task-teams/coastal -ocean-and-shelf-seas-tt/coss-tt-system-information-table/). The domains of most of such systems are restricted to the regions of their interests (Tonani et al. 2015). The unique dynamics of the coastal waters in the Bay of Bengal and the Arabian Sea suggests that, the models configured for simulating and predicting the variability of circulation in the northern Indian Ocean, particularly in the coastal waters around India, need to be carefully designed to account for the effects of both local and remote forcing. At the same time, as most of the users require ocean circulation forecasts for the coastal waters, these models have to be configured at sufficiently high horizontal resolution to resolve the coastal processes with good accuracy. The major challenge faced during the configuration of HOOFS was, thus, the selection of the domain of model setups to balance these requirements, without compromising the quality of the model simulations. At the same time, it may also be noted that the approach taken in the design of HOOFS is quite similar to the other operational systems, as seen from the discussion in the following section.

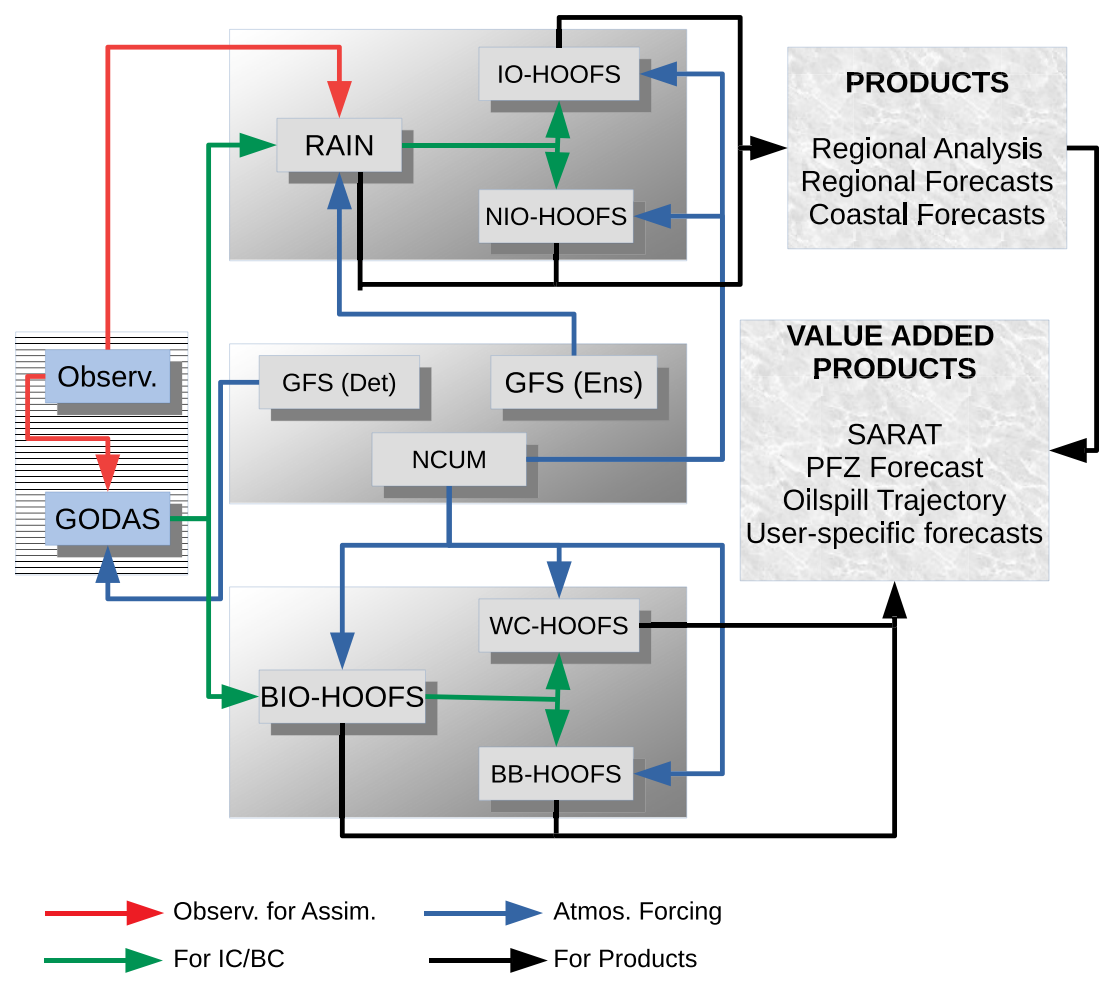

Fig. 1. A schematic representation of the components of HOOFS. GFS (Det.): GFS deterministic atmospheric analysis. GFS (Ens.): GFS ensemble analysis. Observ.: Observations. IC: Initial condition. BC: Boundary condition. Red arrows represent the observational data used for data assimilation in numerical models. Green arrows represent the source of initial and boundary conditions used in various model configurations. Blue arrows indicate the datasets used for the atmospheric forcing in the HOOFS. Black arrows represent the model output used for the generation of analysis, forecast, and value products. 


\section{Design of HOOFS}

A schematic of the architecture of the HOOFS is shown in Fig. 1. HOOFS is configured with ROMS (version 3.7) with two different horizontal resolutions and a data assimilation scheme. ROMS is a free-surface, terrain-following general circulation model developed by Rutgers University, New Jersey, that solves a set of primitive equations in an orthogonal curvilinear coordinate system (Haidvogel et al. 2000; Shchepetkin and McWilliams 2005; Song and Haidvogel 1994). The Indian Ocean configuration of HOOFS (IO-HOOFS) covering the entire tropical Indian Ocean (Fig. 2a) has a spatial resolution of $1 / 12^{\circ}(\sim 9.2 \mathrm{~km})$ while the northern Indian Ocean configuration of HOOFS (NIO-HOOFS) covering part of Arabian Sea (east of $65^{\circ} \mathrm{E}$ ) and the entire Bay of Bengal (Fig. 2b) has a higher spatial resolution of $1 / 48^{\circ}(\sim 2.3 \mathrm{~km})$. Both configurations have 40 sigma levels in the vertical. Bathymetry for these model configurations is prepared from modified ETOPO2 data (Sindhu et al. 2007). The lateral boundary conditions for IO-HOOFS are extracted on a daily basis from INCOIS-Global Ocean Data Assimilation System (GODAS) (Ravichandran et al. 2013) setup covering the global ocean (Fig. 2c). The daily regional analyses (Regional Analysis of Indian Ocean) produced by assimilating in situ temperature and salinity profiles and satellite-measured sea surface temperature (SST) data into IO-HOOFS are used to provide the lateral boundary conditions for NIO-HOOFS. Tracer, momentum, and sea surface height anomaly fields of NIO-HOOFS are initialized using the regional analysis for 1 January 2017. In both NIO-HOOFS and IO-HOOFS, sea surface salinity fields are relaxed to monthly climatology based on the World Ocean Atlas 2009 (WOA2009; Antonov et al. 2010).

While the configurations of NIO-HOOFS and the forecast-mode configuration of IO-HOOFS use K-profile parameterization (KPP) scheme (Large et al. 1994) to parameterize the vertical

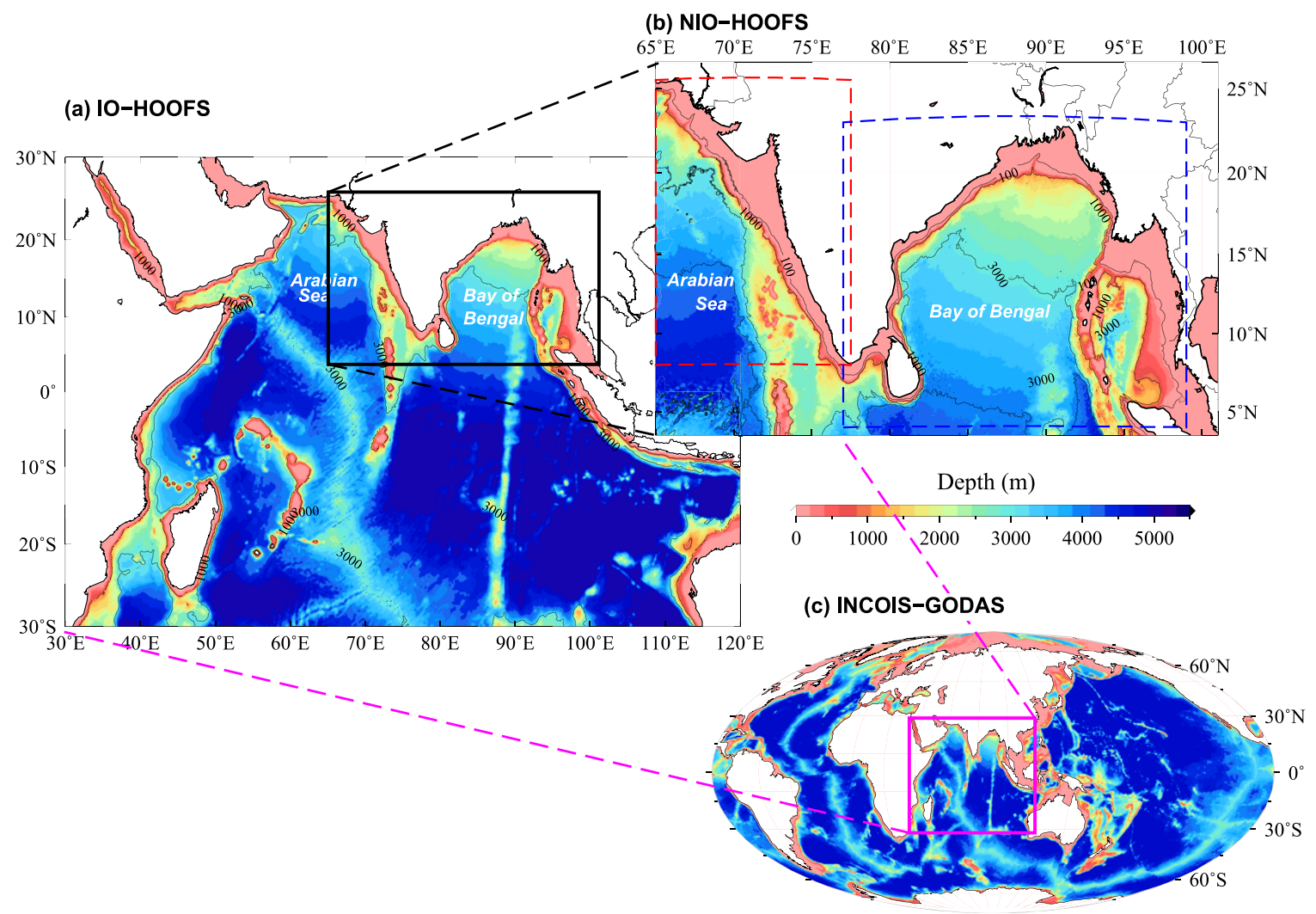

Fig. 2. Maps of domain and bathymetry of the different model configurations. (a) IO-HOOFS/ BIO-HOOFS $\left(30^{\circ} \mathrm{S}-30^{\circ} \mathrm{N}, 30^{\circ}-120^{\circ} \mathrm{E}\right)$, (b) NIO-HOOFS/BIO-HOOFS $\left(3.5^{\circ}-26.5^{\circ} \mathrm{N}, 65^{\circ}-101^{\circ} \mathrm{E}\right)$, and (c) INCOIS-GODAS. Red stippled box in (b) represents the domain of WC-HOOFS $\left(8^{\circ}-26.5^{\circ} \mathrm{N}, 65^{\circ}-77.5^{\circ} \mathrm{E}\right)$ and the blue stippled box represents the domain of BB-HOOFS $\left(4^{\circ}-23^{\circ} \mathrm{N}, 77^{\circ}-99^{\circ} \mathrm{E}\right)$. 
mixing, the IO-HOOFS configuration for preparing the ocean analysis, to which ocean data get assimilated, uses two different mixing schemes, namely, KPP and Mellor and Yamada (MY) 2.5 (Mellor and Yamada 1982) in order to maintain the ensemble spread. More details of the configuration of this system are given in the subsequent section. Harmonic mixing scheme is used for the horizontal mixing of momentum and tracers along the geopotential surfaces (Haidvogel and Beckmann 1999) and bulk parameterization scheme is used for the computation of air-sea fluxes of heat (Fairall et al. 1996) in both IO-HOOFS and NIO-HOOFS configurations. Forecasted atmospheric fields from National Centre for Medium Range Weather Forecasting (NCMRWF) Unified Model (NCUM; Sumit Kumar et al. 2018) configured at a horizontal resolution of $12 \mathrm{~km}$ are used for forcing both NIO-HOOFS and IO-HOOFS setups in the forecast mode. For preparing the regional analysis, the IO-HOOFS is forced by 80 -memberensemble atmospheric forcing produced by NCMRWF using Global Forecast System (GFS) with horizontal resolution of $12 \mathrm{~km}$. NIO-HOOFS configuration also gets updated by forcing it with atmospheric analysis from NCUM on a daily basis. Atmospheric forcing for integrating INCOIS-GODAS is provided from GFS deterministic atmospheric analysis produced by NCMRWF. Tidal forcing is introduced in the NIO-HOOFS with boundary conditions in the southern and western open boundaries are forced by 10 major tidal constituents extracted from TPXO 7.0 model (Egbert and Erofeeva 2002).

It may be noted that biogeochemical modeling module is not incorporated in either IO-HOOFS or NIO-HOOFS. However, forecasts of biogeochemical ocean state are essential for some of the important applications such as forecasts of potential fishing zones (PFZ). Hence, we have configured another biophysical modeling framework based on ROMS (Chakraborty et al. 2019). This includes an Indian Ocean configuration of ROMS (BIO-HOOFS) having the same model domain as that of IO-HOOFS and two high-resolution configurations of ROMS for the west coast of India $\left(8^{\circ}-26.5^{\circ} \mathrm{N}, 65^{\circ}-78^{\circ} \mathrm{E}\right.$; WC-HOOFS) and the Bay of Bengal $\left(4^{\circ}-23^{\circ} \mathrm{N}\right.$, $79^{\circ}-99^{\circ} \mathrm{E}$; BB-HOOFS; Jithin et al. $2017 \mathrm{~b}$ ) at $1 / 48^{\circ}$ resolution. The configuration of BIO-HOOFS is identical to IO-HOOFS, and the configurations (other than model domain) of BB-HOOFS and WC-HOOFS are identical to those of NIO-HOOFS, except that these configurations are integrated with a biogeochemical module (Chakraborty et al. 2018, 2019). The biogeochemical component of these model configurations consists of nitrogen and carbon cycle models based on Fennel et al. (2006) and Wolf-Gladrow (2001), respectively. The partial pressure of carbon dioxide $\left(\mathrm{pCO}_{2}\right)$ is calculated in the surface layer as described in the Fennel et al. (2008). Oxygen is included as model tracer and biogeochemical dynamics of oxygen is described in the model following Fennel et al. (2013). The primary production is estimated by making use of the Vertically Generalized Productivity Model (VGPM; Behrenfeld and Falkowski 1997). All three configurations are forced with atmospheric analysis and forecasts from NCUM.

\section{Regional Analysis of Indian Ocean}

Regional Analysis of Indian Ocean (RAIN) is an ensemble-based ocean data assimilation system (Baduru et al. 2019; Balaji et al. 2018), in which ocean observations are assimilated to the IO-HOOFS (see Fig. 1) configuration using a localized ensemble transform Kalman filter (LETKF) assimilation scheme. LETKF is a relatively new assimilation scheme, which is effective and computationally inexpensive, compared to other ensemble-based Kalman filter (Anderson 2001; Bishop et al. 2001; Wang and Bishop 2003; Ott et al. 2004) since the assimilation of observations occurs in the ensemble space (Hunt et al. 2007). In RAIN, the IO-HOOFS configuration is forced every $6 \mathrm{~h}$ with 80 ensemble fluxes estimated from the atmospheric model GFS (Prasad et al. 2016). The physical parameters like tracer diffusion coefficients and viscosity coefficients slightly vary across the ensemble members. The mixing parameterization schemes also vary across the ensemble members -40 members use KPP (Large et al. 1994) while the remaining 40 members use MY2.5 scheme (Mellor and Yamada 1982). This strategy 
of using two different mixing schemes across the oceanic ensemble members facilitates in maintaining a healthy ensemble spread; one of the typical challenges in ensemble-based data assimilation systems (Baduru et al. 2019). If the spread in the ensemble starts to collapse, the data assimilation system starts laying more confidence on the model states and increasingly less confidence on the observation. Therefore, the analysis, so estimated, bears more weightage of the model state compared to the observation. After some time, the system starts ignoring the observations-a phenomenon known as filter divergence. Apparently, this strategy is not enough to arrest filter divergence. To further protect the system from filter divergence, we also inflate the spread in ensemble members by $10 \%$ after each analysis; that is, the spread in the model error covariance is inflated to offset the reduction in spread after each data assimilation cycle. A horizontal Gaussian profile is used for localization with an e-folding scale of $200 \mathrm{~km}$; that is, the model state at any particular grid is little influenced by observations located beyond $200 \mathrm{~km}$ from that grid. The performance of the system is further improved with the usage of spatially and temporally varying estimates of representation error (RE) as a component of observation error (Sanikommu et al. 2019) to represent the uncertainty in the observations. Detailed validation and performance of RAIN against assimilated and independent variables can be found in Balaji et al. (2018).

Argo profiling floats are the primary source of in situ observations that get assimilated to IO-HOOFS to produce the regional ocean analysis (Fig. 3). The Argo program is part of the Global Ocean Observing System and the data are collected and made freely available by the International Argo Program and the national programs that contribute to it (http:// doi.org/10.17882/42182). In addition to the temperature and salinity profiles from Argo floats, observations from moored buoy arrays such as Research Moored Array for African-AsianAustralian Monsoon Analysis and Prediction (RAMA; McPhaden et al. 2009; www.pmel.noaa .gov/gtmba/), and the data buoys maintained by the National Institute of Ocean Technology (NIOT; www.niot.res.in/niot1/oos_intro.php), Chennai, are also assimilated to the model (Fig. 3).

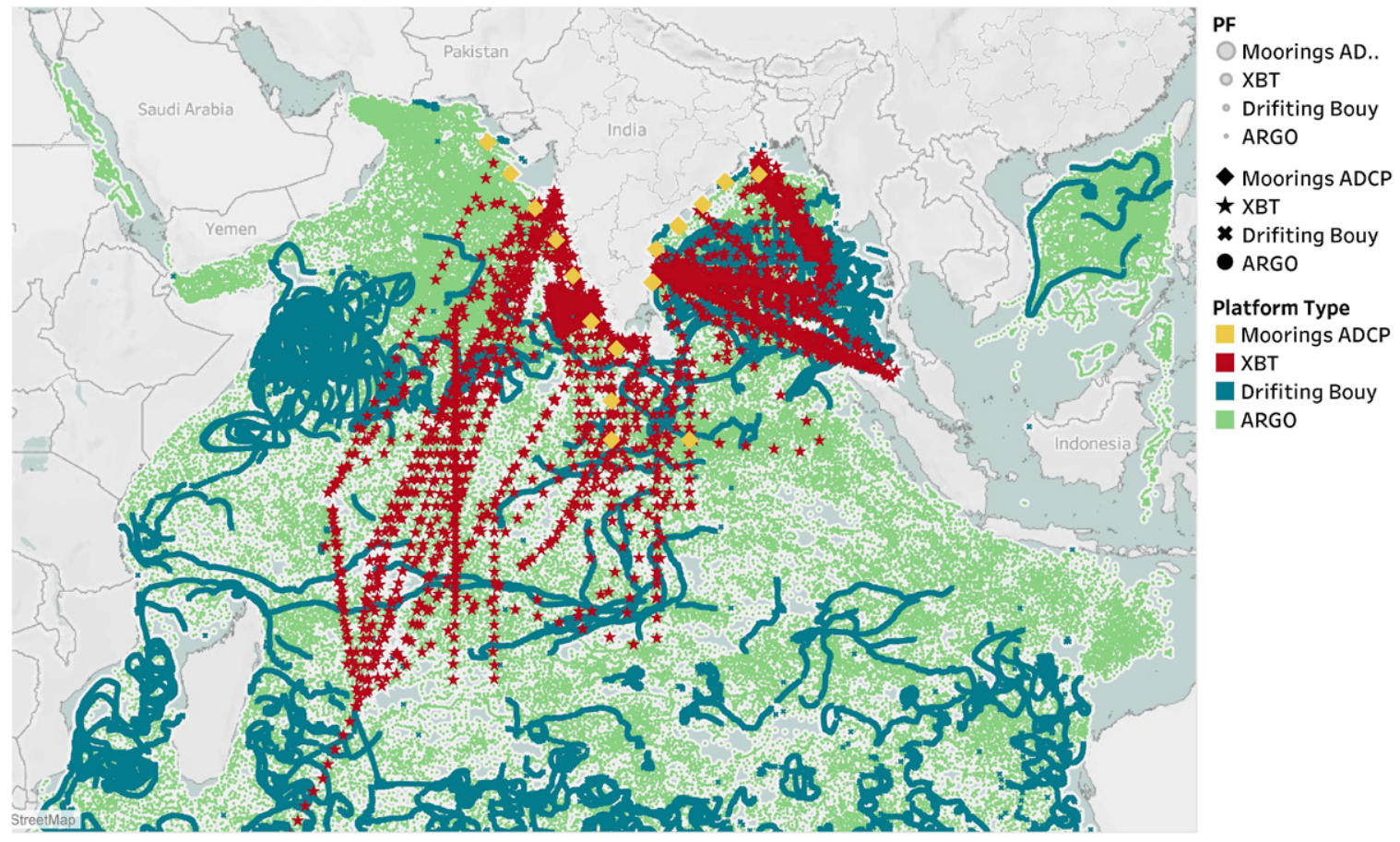

Fig. 3. Trajectories of Argo and drifters in the tropical Indian Ocean for the period from November 2018 to October 2019. Locations from which XBT/XCTD observations are available for ocean reanalysis and the locations of coastal and equatorial ADCP moorings are also shown. The color legend in the upper-left corner explains the platform types. 
Observations received from these platforms in near-real time through Global Telecommunication System (GTS) hub at the India Meteorological Department (IMD) are processed at NCMRWF. The processed observations are then subjected to quality checks before getting assimilated into the ocean models. About $5 \%-10 \%$ of these observations get rejected after quality checks. On average, about 40-50 in situ temperature and salinity profiles are assimilated in RAIN every day. Distribution of observations from Argo, expendable bathythermograph/expendable conductivity-temperature-depth (XBT/XCTD) and surface drifters for the period from November 2018 to October 2019 in the tropical Indian Ocean are shown in Fig. 3. In addition, satellite-based AVHRR SST (level 2) data from NOAA-18, NOAA-19, MetOp-A, and MetOp- $B$, processed based on the multichannel sea surface temperature (MCSST) algorithm (McClain et al. 1985) with satellite zenith angle of $60^{\circ}$ and updated coefficients at INCOIS ground station, are also assimilated in RAIN.

\section{INCOIS-Global Ocean Data Assimilation System}

INCOIS-GODAS, which is a global ocean analysis system in which profiles of temperature and salinity between $60^{\circ} \mathrm{S}$ and $60^{\circ} \mathrm{N}$ are assimilated using 3D-VAR data assimilation scheme into a global configuration of Modular Ocean Model, version 4.0 (MOM4), with a varying horizontal resolution-ranging from $0.25^{\circ}$ in the tropics to $1^{\circ}$ in the extratropics (Ravichandran et al. 2013), plays a critical role in the successful implementation of this HOOFS as it provides the boundary conditions for IO-HOOFS configuration on a daily basis. In addition to the profiles of temperature and salinity from the Argo floats, profiles of temperature from the moored buoy networks such as RAMA buoys, NIOT buoys, Prediction and Research Moored Array in the Tropical Atlantic (PIRATA), and Tropical Atmosphere Ocean (TAO) are also assimilated in INCOIS-GODAS. Altogether, about 800-1,000 profiles of temperature and salinity from global oceans are assimilated into this system every day. The SST in INCOIS-GODAS is relaxed to Optimum Interpolation SST (OISST) provided by National Oceanic and Atmospheric Administration, with a 5-day relaxation time scale. In addition to these data received in real time, INCOIS-GODAS also assimilates profiles of temperature and salinity from regular XBT/XCTD observations in the reanalysis mode (Ravichandran et al. 2013).

Product generation and dissemination. The important products of HOOFS are the analysis and forecasts of ocean general circulation parameters, which are prepared on a daily basis. As the main motivation for setting up the high-resolution operational ocean forecast for the coastal waters around India is the requests from the user community, especially the fishermen, Coast Guard, Navy and the maritime industries, in addition to the ocean analysis/forecasts on a few oceanographic parameters, specific tailor-made products as per the needs of such users are also prepared and disseminated on a regular basis or on demand. The feedbacks from these users on the usefulness of the products provided by INCOIS as well as their suggestions to improve these services are collected directly. INCOIS also organizes regular user interaction meetings with the help of nongovernmental organizations working among the fishermen communities to communicate better with the end users.

The entire operational process, which includes the reception of the processed ocean observations and atmospheric forcing from NCMRWF, their quality checks, integration of models and generation and dissemination of the analysis, forecast and value-added products are fully automated. The preparation of ocean analysis commences at 0930 IST (UTC + 05:30 h) every day, with the reception of processed ocean observations from NCMRWF. These data as well as the atmospheric forcing received from NCMRWF subsequently, are subjected to mandatory quality control procedures. Atmospheric forcing data received from NCMRWF includes 6-hourly analysis for the previous day (in which atmospheric data are assimilated) from NCUM (deterministic) and GFS model (both deterministic and 80-member ensemble) 
and 6-hourly forecasts for the subsequent 5 days from NCUM. Once the quality checks are successful, integration of GODAS gets initiated to produce global ocean analysis from which the southern and eastern boundary conditions for the integration of the RAIN are extracted (as indicated in Fig. 1). This step is followed by the integration of the 80-member RAIN system. Ensemble mean from RAIN is used to provide initial conditions for the integration of IO-HOOFS to generate forecast products for the Indian Ocean basin. After the integration of IO-HOOFS, the integration of NIO-HOOFS takes place. Southern and western boundary conditions for NIO-HOOFS are extracted from RAIN (for the past 5 days) and IO-HOOFS forecasts (for the next 5 days). NIO-HOOFS uses the atmospheric fluxes computed from the atmospheric analysis of NCUM for the previous 5 days and 6-hourly forecasts for the subsequent 5 days from NCUM. Since no data are assimilated in NIO-HOOFS, it is scheduled to reinitialize the model once in every 2 years using initial conditions from RAIN to avoid significant drift from observed state. Note that this reinitialization may not resolve the drift from the observed state due to errors in the lateral and/or surface boundary conditions. On each such reinitialization, the model gets integrated for at least 6 months before starting the forecast runs. This is to ensure that sufficient spinup of the high-resolution model takes place before the forecasts are made. Every day, 3-hourly forecasts of ocean circulations for subsequent 5 days are generated based on the model simulations (both IO-HOOFS and NIO-HOOFS). As no observational data gets assimilated to BIO-HOOFS, WC-HOOFS, and BB-HOOFS configurations, the initial conditions for integrating these models in forecast mode are taken from the previous day's free model simulation forced with atmospheric analysis provided by NCUM. Lateral boundary conditions of tracer and momentum for the BIO-HOOFS are extracted from INCOIS-GODAS and of the biogeochemical parameters are prescribed from monthly climatological values (WOA2009; Garcia et al. 2010a,b). Integration of BIO-HOOFS is followed by the integration of WC-HOOFS and BB-HOOFS. Lateral boundary conditions for these models are extracted from BIO-HOOFS.

Images and data of the ocean analysis for the previous 15 days are prepared based on RAIN and made available to the public on the INCOIS web page (https://incois.gov.in). Forecasts of physical parameters in the coastal waters and Indian Ocean are prepared based on the simulations from NIO-HOOFS and IO-HOOFS, respectively. Forecasts of biogeochemical parameters are extracted from the simulations of BB-HOOFS and WC-HOOFS. General forecasts of the parameters such as SST, depth of the mixed layer, surface currents, and depth of the $20^{\circ} \mathrm{C}$ isotherm are regularly prepared from the model forecast fields and their images and data are posted on the web page of Ocean State Forecast (OSF) services of INCOIS (Fig. 4; https://incois .gov.in/portal/osf/osf.jsp). INCOIS make use of many modern communication channels and join hands with nongovernmental organizations to reach out to the users, especially the livelihoodearning fishermen, with the operational products. Specific products as per the requirements of different users such as Indian Coast Guard, Indian Navy, offshore industries, researchers, and shipping industry are prepared and provided on request.

\section{Verification of ocean analysis and forecasts}

The Council of Scientific and Industrial Research (CSIR)-National Institute of Oceanography (NIO), Goa, with the financial support from INCOIS, has been maintaining 17 acoustic Doppler current profiler (ADCP) moorings at about 100- and 1,000-m depths, respectively, on the continental shelf and slope at various locations along the Indian coastal regions since 2008 (Amol et al. 2014; Mukherjee et al. 2014). Locations of these ADCPs are shown in Fig. 3. Comparisons of the simulated coastal alongshore currents by NIO-HOOFS and zonal currents in the deep ocean from RAIN with the observations from coastal ADCPs and RAMA moored buoys are shown in Fig. 5. RAIN has a very high skill (correlation coefficient is about 0.8 at equator) in simulating the currents in the deep ocean, particularly in the equatorial regions. NIO-HOOFS also could simulate the observed variability in the alongshore currents off both 


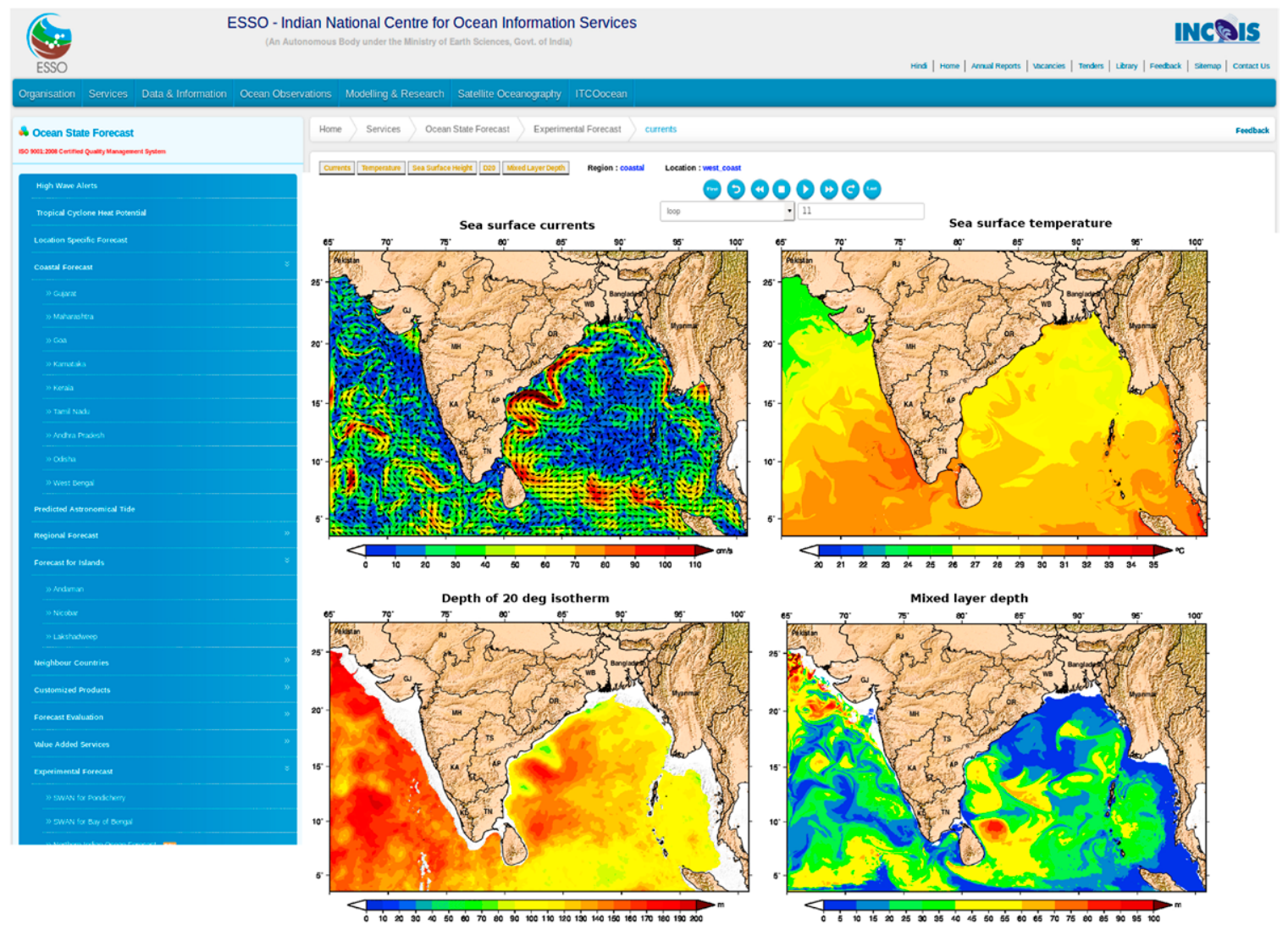

Fig. 4. Examples of forecast products generated from NIO-HOOFS (1200 IST 20 Mar 2020) including (top left) sea surface currents $\left(\mathrm{cm} \mathrm{s}^{-1}\right)$, (top right) sea surface temperature $\left({ }^{\circ} \mathrm{C}\right)$, (bottom left) depth of $20^{\circ} \mathrm{C}$ isotherms, and (bottom right) mixed layer depth (m).

(a) Goa slope

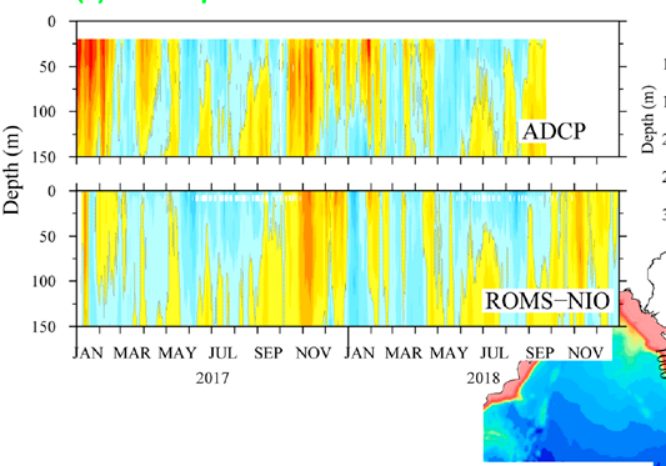

(c) RAMA $-80.5^{\circ} \mathrm{E}$

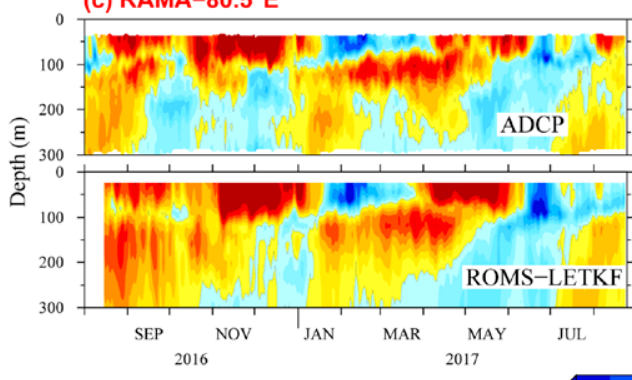

(b) Cuddalore slope

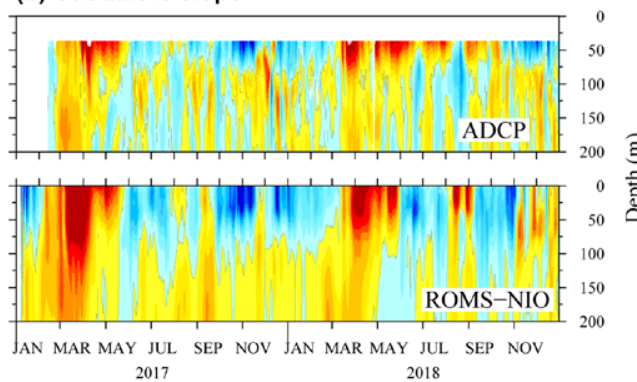

(d) RAMA- $90^{\circ} \mathrm{E}$

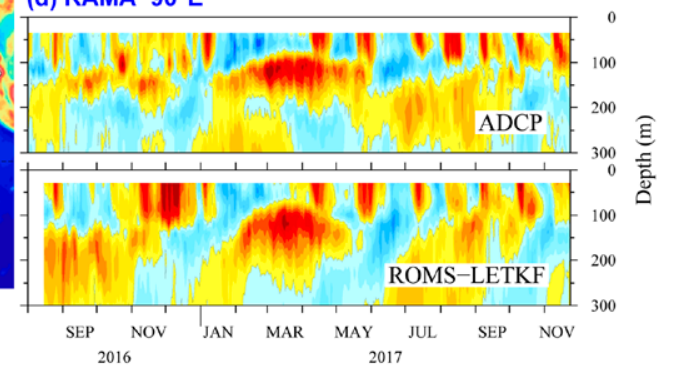

Fig. 5. Comparison of simulated and observed vertical profiles of (a),(b) coastal and (c),(d) equatorial currents. Locations of the ADCP moorings (green and red triangles) are shown on the map. In the coastal (equatorial) regions, alongshore (zonal) currents are used for the comparison and positive velocity values represent the poleward (eastward) flow. Statistical comparison of currents including correlation and RMSE on the slope off Goa in green, off Cuddalore in black, and along equator at $85^{\circ} \mathrm{E}$ in red and $90^{\circ} \mathrm{E}$ in blue is also shown. 
the east and west coasts of India with good accuracy. It may be noted that the skill is slightly better (correlation coefficient $=0.55$ ) for the west coast location (off Goa) compared to the east coast (correlation coefficient $=0.49$ ) location (Cuddalore). Lower skill in the east coast may be due to the presence of strong intraseasonal variation in the currents in both surface and subsurface as described in Mukherjee et al. (2017) and Francis et al. (2020). Further, the system has a very good skill in predicting the thermal structure of the deep and coastal ocean, even with 3-5-day lead time (Fig. 6). The correlation between the observed and the predicted temperature are very high (0.7-0.9) and the RMSEs are less than $1^{\circ} \mathrm{C}$ in the top $50 \mathrm{~m}$ of the ocean at most of the buoy locations. Note that sudden SST drop during the passage of tropical storms (depicted by gray shading in Fig. 6) was accurately predicted by the system even with 3-day lead time.

Compared to RAIN/IO-HOOFS or other global ocean analysis systems such as GODAS, the variability in the circulation and temperature, both in surface and subsurface coastal waters,

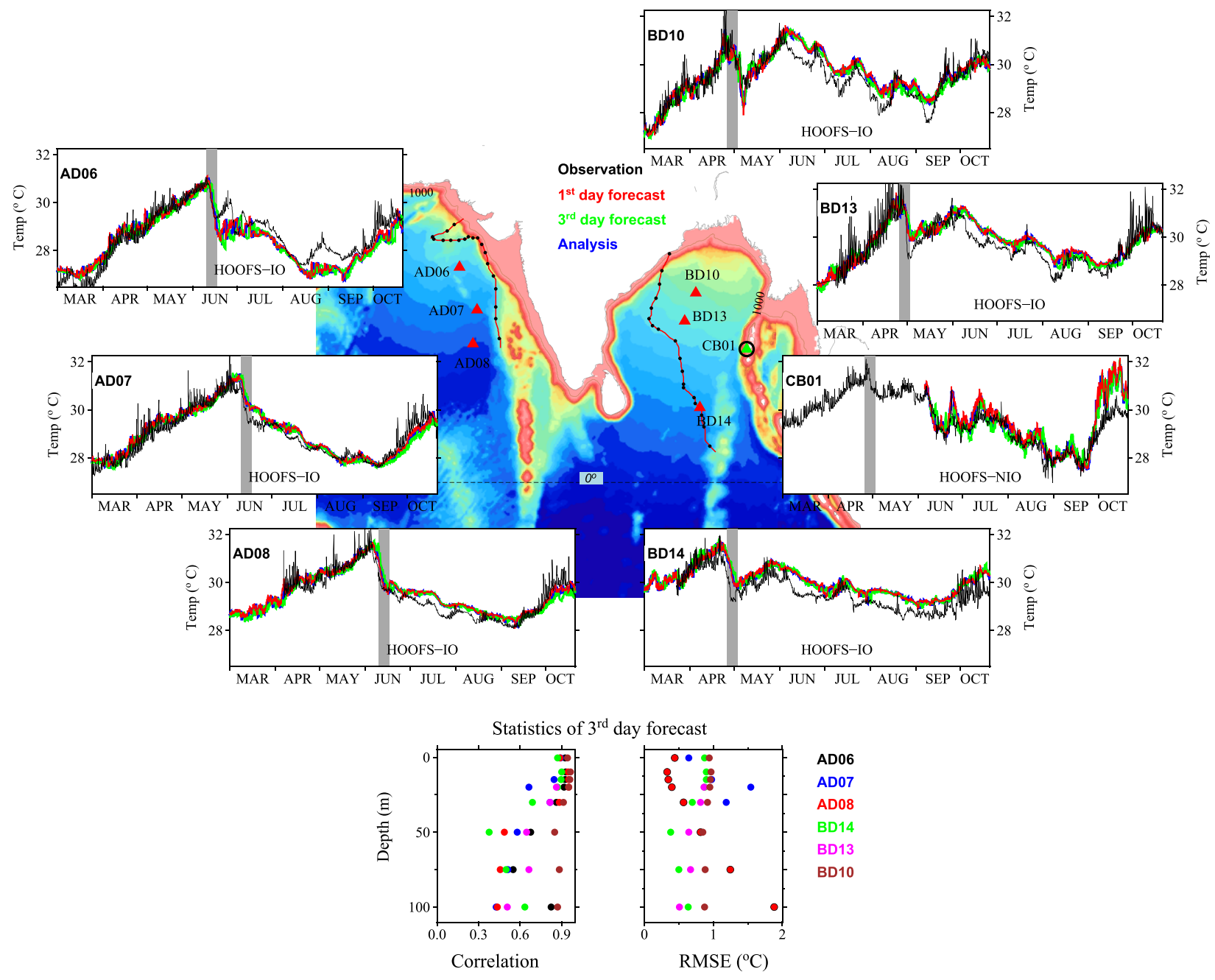

Fig. 6. (top) Map showing locations of six Ocean Moored Buoy Network in Northern Indian Ocean (OMNI) moorings (red triangles with black circle) and a coastal buoy (green triangle with black circle) used to validate the predicted sea surface temperature in the northern Indian Ocean by HOOFS. The red line with black circles on the map indicates the tracks of Cyclone Vayu formed in the Arabian Sea (10-17 Jun 2019) and Fani formed in the Bay of Bengal (30 Apr-5 May 2019). Time series plots show the comparison of SST forecast (red, green, and blue lines) from HOOFS with observations ( 3 hourly) from the OMNI moorings (black line). The vertical gray-shaded region indicates the passing time of Cyclone Vayu in the Arabian Sea (AD06, AD07, and AD08) and Cyclone Fani in Bay of Bengal (BD14, CB01, BD13, and BD10). (bottom) Statistics (correlation and RMSE) of the third-day forecast of temperature in the upper-100-m water column at the different mooring locations. 
are better simulated in NIO-HOOFS. In addition, some recent studies based on the simulations from the $1 / 48^{\circ}$ ROMS configuration for the Bay of Bengal and Arabian Sea demonstrated that this model configuration have very good skill in simulating the variability associated with tides and coastally trapped waves on the shelf regions (Jithin et al. 2019; N. Anup et al. 2020, unpublished manuscript; Subeesh 2019). These improvements are mainly due to the finetuning of the model configuration such as background diffusivity and viscosity and bottom drag coefficients to make it suitable for the coastal applications, realistic representation of coastal bathymetry, and realistic interaction of mesoscale eddies with topography (Jithin et al. 2017a; Francis et al. 2020).

\section{Applications}

In addition to the routine forecasts of ocean general circulation parameters, INCOIS also provides value-added services based on the HOOFS forecasts. Search and Rescue Aid Tool (SARAT) and PFZ forecast system are a few among such products.

SARAT. To assist the Indian Coast Guard, which is the nodal agency to carry out search and rescue missions to locate missing/stranded objects/persons in the sea, a SARAT has been set up by INCOIS. SARAT is based on the Leeway model (Breivik and Allen 2008), which is a Monte Carlo stochastic ensemble trajectory model that calculates motion of objects on the sea surface under the influence of wind and surface currents. Forecasts of ocean currents from HOOFS and surface wind from NCUM are used in SARAT to estimate the drift of the objects from their last known position. However, in most of the real cases, accurate information on the last-known position and time may not be available with the search and rescue agencies. To address this operational difficulty, an approximate last-known position and time are chosen, and an ensemble of scenarios are simulated by randomly scattering a number of identical objects around the last known position or over the suspected area. The radius of scattering is determined based on the confidence in the initial estimates. All these ensemble members are then subjected to wind and ocean currents and their trajectories are monitored. The search region is defined as a convex hull of the end positions of these trajectories. The entire search region is then categorized into smaller regions according to probability of finding the lost object. The output from the mathematical model is simplified and converted into bulletins and graphical interface to make it easier for the users to identify the search region. A sample output of SARAT, displaying the predicted search area of a simulated drifting buoy versus the observed buoy trajectory, is shown in Fig. 7.

Potential Fishing Zone forecasting system. The PFZ advisories generated and disseminated by INCOIS have significant impact on the livelihood of fishermen in India. The improvised fishermen often spend exorbitant time and fuel in search of a viable fishing ground to cast the nets. The extra time and fuel spent at sea leads in heavy loss or in generating meager income affecting their livelihood. PFZ advisories are generated based on the observations that the regions in which significant SST gradient and high Chl-a concentration are present have higher potential for fish aggregation

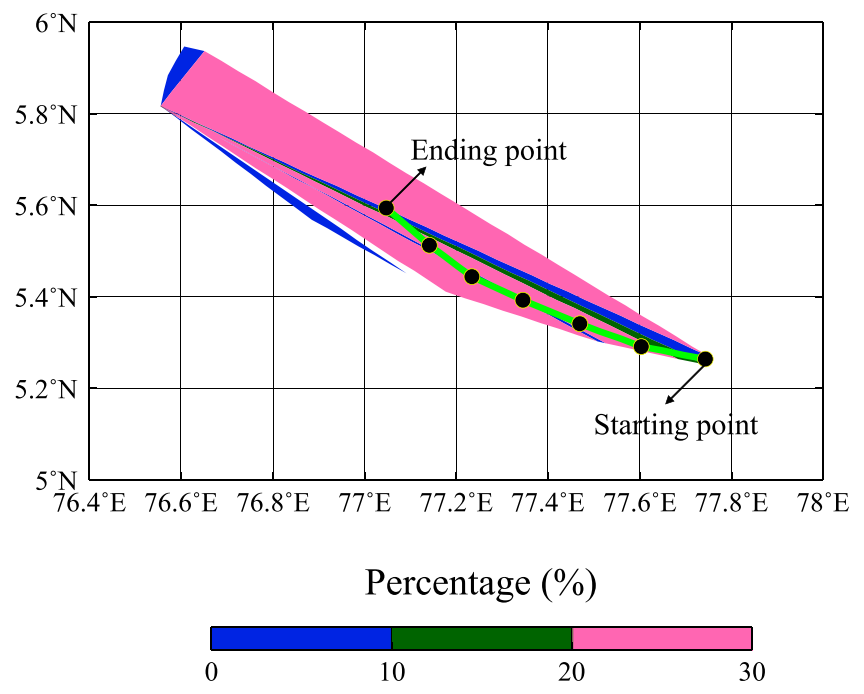

Fig. 7. Observed trajectory (green line with black dot) of a surface drifter (ID 65701980) in the Indian Ocean during 0600 IST 3 Mar to 1800 IST 4 Mar 2019 superimposed on the predicted search region (black box) and probability derived by SARAT using the initial position $\left(5.264^{\circ} \mathrm{N}, 77.743^{\circ} \mathrm{E}\right)$. 
(Dwivedi et al. 2005; Kumar et al. 2012; Nayak et al. 2007; Solanki et al. 2001a,b, 2003, 2005). However, often it becomes a major challenge to retrieve SST/Chl-a data from satellite images, particularly from the regions under cloud cover. Considering these factors, INCOIS developed a PFZ forecasting system based on the outputs of HOOFS, which can overcome the operational difficulties in issuing PFZ advisories due to nonavailability of data and provide the forecasts of potential fishing grounds based on the HOOFS forecasts. In this system, the thermal fronts in the coastal waters are identified from the SST forecasts of WC-HOOFS and BB-HOOFS using the algorithms prescribed by Cayula and Cornillon (1992). Canny (1986) algorithm is employed to detect Chl-a fronts from BIO-HOOFS. The frontal vectors, thus delineated from the forecasts of SST and Chl-a, are superimposed on regional maps to identify the common fronts (Fig. 8). A tolerance limit of $15 \mathrm{~km}$ has been fixed to identify common fronts derived from both SST and Chl-a (Nammalwar et al. 2013; Sarma et al. 2018). Considering the operational requirements, PFZ forecasts are issued only for 3 days. Details of the PFZ forecasting systems and the validation of PFZ forecasts are given in Chakraborty et al. (2019).

\section{Summary and way forward}

Most important objective of the HOOFS project is to develop an operational ocean forecast and analysis system comprising high-resolution numerical ocean models and data assimilation
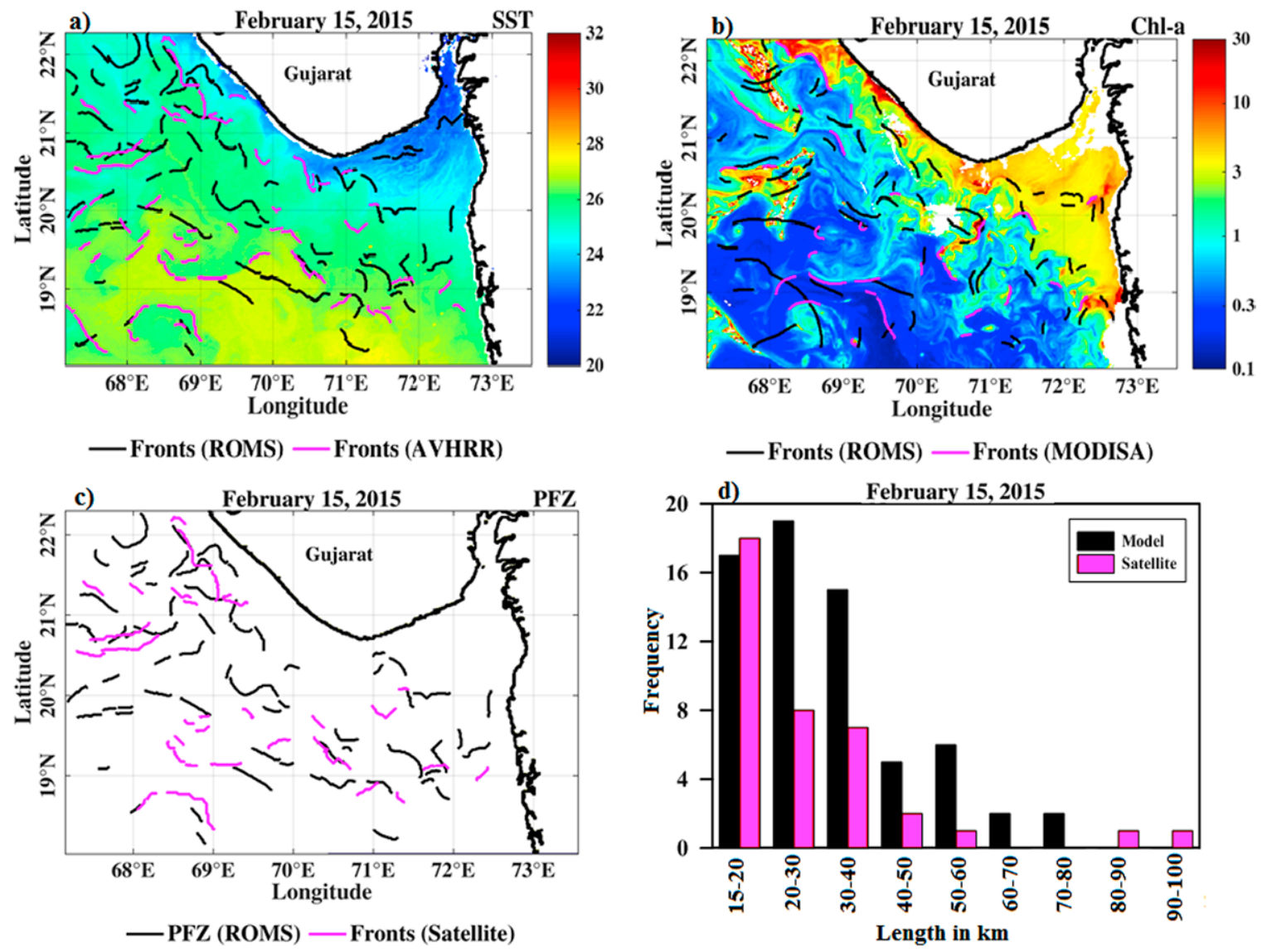

Fig. 8. (a) Comparison of SST fronts detected from satellite (pink lines) and HOOFS (black lines) data on $15 \mathrm{Feb} 2015$. Overlaid is the SST $\left({ }^{\circ} \mathrm{C}\right)$ from AVHRR sensor onboard MetOp-2 satellite (1.1-km spatial resolution). (b) As in (a), but overlaid is Chl-a $\left(\mathrm{mg} \mathrm{m}^{-3}\right)$ in logarithmic scale from MODIS Aqua (1-km spatial resolution). (c) Comparison of PFZ generated by combining the fronts detected from SST and Chl-a using satellite observation (pink lines) and simulations from HOOFS (black lines) data on 15 Feb 2015. (d) Histogram consisting of the binned frequency of the identified PFZs derived from satellite (pink) and HOOFS (black) with respect to length of PFZs as class interval of $5 \mathrm{~km}$ for 15 Feb 2015 (Chakraborty et al. 2019). 
schemes. ROMS configurations with spatial resolution of $1 / 12^{\circ}$ for the tropical Indian Ocean (IO-HOOFS) and $1 / 48^{\circ}$ for the northern Indian Ocean (NIO-HOOFS) have been set up as part of this project. In situ profiles of temperature and salinity and the satellite-measured SST data are assimilated in the basin-scale configuration of ROMS using a LETKF-based data assimilation scheme. Analysis and forecast products of physical oceanographic parameters are prepared based on these configurations. A few applications such as Search and Rescue Aid Tool and Potential Fishing Zone forecast system are also developed as part of the project.

There are many regional operational ocean forecasting systems operated worldwide such as European Copernicus Marine Environment Monitoring System (CMEMS; http://marine.copernicus .eu), the Australian BlueLink (www.csiro.au), the Forecast Ocean Assimilation Model (FOAM) of the Met Office (www.metoffice.gov.uk/), NOAA Real Time Ocean Forecast System (https://polar .ncep.noaa.gov/ofs/), the ocean forecast system of National Marine Environmental Forecast System, China (https://nmefc.gov.cn/), and Multivariate Ocean Variational Estimate (https:// ds.data.jma.go.jp/) of Meteorological Research Institute of Japan. A complete list of these systems as well as the details of their configurations can be found in the web page of GODAE Ocean Predict (www.godae-oceanview.org/science/ocean-forecasting-systems/). However, there are only 8-10 global-to-regional ocean forecasting systems operated worldwide (i.e., which are similar to HOOFS with multiple nested models (Tonani et al. 2015). The HOOFS configuration has significantly higher spatial resolution in the northern Indian Ocean compared to other global/regional systems and the ocean models are specifically tuned for the coastal waters of South Asian countries considering its unique circulation features. Apart from the data available through GTS, data from the moored buoys deployed and maintained by NIOT are also assimilated into IO-HOOFS.

In the present configuration of HOOFS, lateral boundary conditions for the NIO-HOOFS are being extracted from IO-HOOFS in offline mode. Often this introduces errors in the exchanges of tracer and momentum at the boundaries due to spatial and temporal interpolation according to the frequency at which the boundary conditions are exchanged. It also causes operational inconvenience as the boundary conditions are extracted using a third-party software. To overcome this, it is planned to nest the two configurations online, a technique that has already been tested by ROMS developers. Another drawback of the present system is that sea level anomaly data are not assimilated in GODAS as well as in RAIN. It is expected that the ocean analysis, particularly ocean currents, will improve with the assimilation of sea level anomaly data. It is also important to incorporate biogeochemical modeling module in NIO-HOOFS and assimilate biogeochemical parameters in IO-HOOFS so that PFZ forecasts can be generated from the same integrated system that is used to generate the forecasts of ocean general circulation features. Further, as most users of INCOIS operational forecasts have strong interests in the waters near the coasts, it is also planned to set up a shelf sea forecast system to provide accurate forecasts in this region. Assimilation of data on surface currents, measured by high-frequency radars installed along the east coast of India, in this shelf sea model is expected to improve the accuracy of coastal forecasts.

Large influx of freshwater from the nearby rivers to the Bay of Bengal, particularly to the head of the bay, poses a major challenge in the modeling of ocean circulation in this region. Due to the presence of freshwater, the head of the bay is highly stratified with relatively shallow mixed layer depths. While there have been a few studies suggesting the importance of the inclusion of freshwater discharge on the simulation of the circulation in the northern bay (e.g., Vinayachandran and Kurian 2007), inclusion of river discharge to an operational forecast system remains as a challenge due to the nonavailability of these data in near-real time. Availability of satellite-based estimates of river discharge data (Papa et al. 2012) is promising and hence, INCOIS is now exploring the possibility get similar data on a nearreal-time basis. 
Acknowledgments. Authors gratefully acknowledge the comments and suggestions made by Dr. Satish Shetye and Prof. B. N. Goswami, cochairs of the Project Monitoring Committee (PMC) of the HOOFS project during 2012-17 and other members of the PMC, which led to the successful implementation of this project. Authors also gratefully acknowledge Dr. M. Rajeevan, Secretary to Government of India, Ministry of Earth Sciences, Dr. Shailesh Naik, former Secretary to Government of India, Ministry of Earth Sciences and program officers of the Ministry of Earth Sciences for their continued support to implement this project at INCOIS. Financial support from MoES to implement the HOOFS and O-MASCOT projects are gratefully acknowledged. Support from the HPC support team, both at IITM Pune and NCMRWF Noida and the support of the computer and IT team of INCOIS were critical for the successful implementation of the project. Authors thank developers of ROMS for making the model publicly available. Arya Paul and Siva Reddy gratefully acknowledge the training on LETKF by Eugenia Kalnay, Travis Sluka, and Steve Penny at the University of Maryland under the Monsoon Mission-I project. The SST in INCOIS-GODAS is relaxed to Optimum Interpolation SST provided by National Oceanic and Atmospheric Administration (OISST; www.esrl.noaa.gov/psd/data/gridded/data.noaa .oisst.v2.highres.html). Authors thank three anonymous reviewers for their suggestions and comments, which helped to improve the paper. This is INCOIS contribution No. 376.

\section{References}

Amol, P., and Coauthors, 2012. Observational evidence from direct current measurements for propagation of remotely forced waves on the shelf off the west coast of India. J. Geophys. Res.: Oceans, 117, C05017, https://doi .org/10.1029/2011JC007606.

_ the West India Coastal Current on the continental slope. J. Earth Syst. Sci., 123, 1045-1074, https://doi.org/10.1007/s12040-014-0449-5.

Anderson, J. L., 2001: An ensemble adjustment Kalman filter for data assimilation. Mon. Wea. Rev., 129, 2884-2903, https://doi.org/10.1175/1520-0493 (2001)129<2884:AEAKFF>2.0.C0;2.

Antonov, J. I., and Coauthors, 2010: Salinity. Vol. 2, World Ocean Atlas 2009, NOAA Atlas NESDIS 69, 184 pp.

Baduru, B., B. Paul, D. S. Banerjee, S. Sanikommu, and A. Paul, 2019: Ensemble based regional ocean data assimilation system for the Indian Ocean: Implementation and evaluation. Ocean Modell., 143, 101470, https://doi.org/10 .1016/j.ocemod.2019.101470.
Balaji, B., D. S. Banerjee, B. Paul, S. Sivareddy, P. Francis, A. Chatterjee, and A. Paul, 2018: LETKF-ROMS: An improved predictability system for the Indian Ocean. INCOIS Tech. Rep. ESSO-INCOIS-MDG-TR-03, 96 pp., http://moeseprints. incois.gov.in/4572.

Behrenfeld, M. J., and P. G. Falkowski, 1997: Photosynthetic rates derived from satellite-based chlorophyll concentration. Limnol. Oceanogr., 42, 1-20, https:// doi.org/10.4319/lo.1997.42.1.0001.

Bishop, C. H., B. J. Etherton, and S. J. Majumdar, 2001: Adaptive sampling with the ensemble transform Kalman filter. Part I: Theoretical aspects. Mon. Wea. Rev., 129, 420-436, https://doi.org/10.1175/1520-0493(2001)129<0420:ASWTET $>2.0 . \mathrm{CO} ; 2$.

Breivik, 0., and A. Allen, 2008: An operational search and rescue model for the Norwegian Sea and the North Sea. J. Mar. Syst., 69, 99-113, https://doi.org /10.1016/j.jmarsys.2007.02.010.

Butman, B., P. S. Alexander, A. Scotti, R. C. Beardsley, and S. P. Anderson, 2006: Large internal waves in Massachusetts Bay transport sediments offshore. 
Cont. Shelf Res., 26, 2029-2049, https://doi.org/10.1016/j.csr.2006.07 .022 .

Canny, J., 1986: A computational approach to edge detection. IEEE Trans. Pattern Anal. Mach. Intell., 8, 679-698, https://doi.org/10.1109/TPAMI.1986.4767851.

Cayula, J. F., and P. Cornillon, 1992: Edge detection algorithm for SST images. J. Atmos. Oceanic Technol., 9, 67-80, https://doi.org/10.1175/1520-0426 (1992)009<0067:EDAFSI>2.0.CO;2.

Chakraborty, K., K. Nimit, A. Akhand, S. Prakash, A. Paul, J. Ghosh, T. U. Bhaskar, and A. Chanda, 2018: Modeling the enhancement of sea surface chlorophyll concentration during the cyclonic events in the Arabian Sea. J. Sea Res., 140, 22-31, https://doi.org/10.1016/j.seares.2018.07.003.

_ S. Maity, A. A. Lotliker, A. Samanta, J. Ghosh, N. K. Masuluri, N. Swetha, and R. P. Bright, 2019: Modelling of marine ecosystem in regional scale for short term prediction of satellite-aided operational fishery advisories. J. Oper. Oceanogr., 12, S157-S175, https://doi.org/10.1080/1755876X.2019.1574951.

Chatterjee, A., D. Shankar, J. P. McCreary, P. N. Vinayachandran, and A. Mukherjee, 2017: Dynamics of Andaman Sea circulation and its role in connecting the equatorial Indian Ocean to the Bay of Bengal. J. Geophys. Res. Oceans, 122, 3200-3218, https://doi.org/10.1002/2016JC012300.

Chen, G., Y. Li, Q. Xie, and D. Wang, 2018: Origins of eddy kinetic energy in the Bay of Bengal. J. Geophys. Res. Oceans, 123, 2097-2115, https://doi.org/10 .1002/2017JC013455.

Dwivedi, R. M., H. U. Solanki, S. R. Nayak, D. Gulati, and V. S. Somvanshi, 2005: Exploration of fishery resources through integration of ocean colour with sea surface temperature: Indian experience. Ind. J. Marine Sci., 34, 430-440, http://nopr.niscair.res.in/handle/123456789/1577.

Egbert, G. D., and S. Y. Erofeeva, 2002: Efficient inverse modeling of barotropic ocean tides. J. Atmos. Oceanic Technol., 19, 183-204, https://doi.org/10.1175 /1520-0426(2002)019<0183:EIMOBO>2.0.C0;2.

Fairall, C. W., E. F. Bradley, D. P. Rogers, J. B. Edson, and G. S. Young, 1996: Bulk parameterization of air-sea fluxes for Tropical Ocean-Global Atmosphere Coupled-Ocean Atmosphere Response Experiment. J. Geophys. Res., 101, 3747-3764, https://doi.org/10.1029/95JC03205.

Fennel, K., J. Wilkin, J. Levin, J. Moisan, J. O'Reilly, and D. Haidvogel, 2006: Nitrogen cycling in the middle Atlantic bight: Results from a three-dimensional model and implications for the North Atlantic nitrogen budget. Global Biogeochem. Cycles, 20, 3007, https://doi.org/10.1029/2005GB002456.

_ _ - M. Previdi, and R. Najjar, 2008: Denitrification effects on air-sea $\mathrm{CO}_{2}$ flux in the coastal ocean: Simulations for the northwest North Atlantic. Geophys. Res. Lett., 35, L24608, https://doi.org/10.1029/2008GL036147.

_ _ J. Hu, A. Laurent, M. Marta-Almeida, and R. Hetland, 2013: Sensitivity of hypoxia predictions for the northern Gulf of Mexico to sediment oxygen consumption and model nesting. J. Geophys. Res. Oceans, 118, 990-1002, https://doi.org/10.1002/jgrc.20077.

Francis, P.A., P. N. Vinayachandran, and S. S. C. Shenoi, 2013: The Indian Ocean Forecast System. Curr. Sci., 104, 1354-1368, www.currentscience.ac.in/Volumes /104/10/1354.pdf.

_ A. K. Jithin, A. Chatterjee, A. Mukherjee, D. Shankar, P. N. Vinayachandran, and S. S. V. S. Ramakrishna, 2020: Structure and dynamics of undercurrents in the western boundary current of the Bay of Bengal. Ocean Dyn., 70, 387-404, https://doi.org/10.1007/s10236-019-01340-9.

Garcia, H. E., R. A. Locarnini, T. P. Boyer, J. I. Antonov, O. K. Baranova, M. M. Zweng, and D. R. Johnson, 2010a: Dissolved Oxygen, Apparent Oxygen Utilization, and Oxygen Saturation. Vol. 3, World Ocean Atlas 2009, NOAA Atlas NESDIS 70, $344 \mathrm{pp}$.

— — - — - - M. M. Zweng, O. K. Baranova, and D. R. Johnson, 2010b: Nutrients (Phosphate, Nitrate, Silicate). Vol. 4, World Ocean Atlas 2009, NOAA Atlas NESDIS 71, 398 pp.

Girishkumar, M. S., M. Ravichandran, and W. Han, 2013: Observed intraseasonal thermocline variability in the Bay of Bengal. J. Geophys. Res. Oceans, 118, 3336-3349, https://doi.org/10.1002/jgrc.20245.

Haidvogel, D. B., and A. Beckmann, 1999: Numerical Ocean Circulation Modeling. Imperial College Press, $344 \mathrm{pp}$.
- H. G. Arango, K. Hedstrom, A. Beckmann, P. Malanotte-Rizzoli, and A. F. Shchepetkin, 2000: Model evaluation experiments in the North Atlantic basin: Simulations in nonlinear terrain-following coordinates. Dyn. Atmos. Oceans, 32, 239-281, https://doi.org/10.1016/S0377-0265(00)00049-X.

Hunt, B. R., E. J. Kostelich, and I. Szunyogh, 2007: Efficient data assimilation for spatiotemporal chaos: A local ensemble transform Kalman filter. Physica $D$, 230, 112-126, https://doi.org/10.1016/j.physd.2006.11.008.

Jithin, A. K., and Coauthors, 2017a: Observed tidal currents on the continental shelf off the east coast of India. Cont. Shelf Res., 141, 51-67, https://doi .org/10.1016/j.csr.2017.04.001.

_ _ P. A. Francis, A. Chatterjee, K. Suprit, and V. Fernando, 2017b: Validation of the simulations by the High-Resolution Operational Ocean Forecast and Reanalysis System (HOOFS) for the Bay of Bengal. INCOIS Tech. Rep. ESSO/ INCOIS/ISG/TR/01, 58 pp., http://moeseprints.incois.gov.in/4418/.

_ - A. S. Unnikrishnan, and S. S. V. S. Ramakrishna, 2019: Modeling of internal tides in the western Bay of Bengal: Characteristics and energetics. J. Geophys. Res. Oceans, 124, 1-27, https://doi.org/10.1029/2019JC015319.

_ M. P. Subeesh, P. A. Francis, and S. S. V. S. Ramakrishan, 2020: Intensification of tidally generated internal waves in the north-central Bay of Bengal. Sci. Rep., 10, 6059, https://doi.org/10.1038/s41598-020-62679-4.

Kumar, M. N., T. S. Kumar, N. N. Swetha, S. Maity, and U. Jemima, 2012: A comparative study on feasibility of utilization of GHRSST product for operational generation of potential fishing zone (PFZ) advisories in India. Int. J. Earth Sci. Eng., 5, 240-246, http://hdl.handle.net/123456789/12934.

Large, W. G., J. C. McWilliams, and S. C. Doney, 1994: Oceanic vertical mixing: A review and a model with a nonlocal boundary layer parameterization. Rev. Geophys., 32, 363-403, https://doi.org/10.1029/94RG01872.

Mandal, S., S. Sil, A. Gangopadhyay, B. K. Jena, and R. Venkatesan, 2020: On the nature of tidal asymmetry in the Gulf of Khambhat, Arabian Sea using the HF radar surface currents. Estuarine Coastal Shelf Sci., 232, 106481, https://doi .org/10.1016/j.ecss.2019.106481.

McClain, E. P., W. G. Pichel, and C. C. Walton, 1985: Comparative performance AVHRR based multichannel sea surface temperatures. J. Geophys. Res., 90, 11587-11 601, https://doi.org/10.1029/JC090iC06p11587.

McCreary, J. P., P. K. Kundu, and R. L. Molinari, 1993: A numerical investigation of dynamics, thermodynamics and mixed-layer processes in the Indian Ocean. Prog. Oceanogr., 31, 181-244, https://doi.org/10.1016/0079-6611(93)90002 $-U$.

McPhaden, M. J., and Coauthors, 2009: RAMA: The Research Moored Array for African-Asian-Australian Monsoon Analysis and Prediction. Bull. Amer. Meteor. Soc., 90, 459-480, https://doi.org/10.1175/2008BAMS2608.1.

Mellor, G. L., and T. Yamada, 1982: Development of a turbulence closure model for geophysical fluid problems. Rev. Geophys., 20, 851, https://doi.org/10.1029 /RG020i004p00851.

Mukherjee, A., and Coauthors, 2014: Observed seasonal and intraseasonal variability of the East India Coastal Current on the continental slope. J. Earth Syst. Sci., 123, 1197-1232, https://doi.org/10.1007/s12040-014-0471-7.

__ D. Shankar, A. Chatterjee, and P. N. Vinayachandran, 2017: Numerical simulation of the observed near-surface East India Coastal Current on the continental slope. Climate Dyn., 50, 3949-3980, https://doi.org/10.1007/s00382 -017-3856-x.

- A. Chatterjee, and P. A. Francis, 2019: Role of Andaman and Nicobar Islands in eddy formation along western boundary of the Bay of Bengal. Sci. Rep., 9, 10152, https://doi.org/10.1038/s41598-019-46542-9.

Mukhopadhyay, S., D. Shankar, S. G. Aparna, and A. Mukherjee, 2017: Observations of the sub-inertial, near-surface East India Coastal Current. Cont. Shelf Res., 148, 159-177.

Nammalwar, P., S. Satheesh, and R. Ramesh, 2013: Applications of remote sensing in the validations of potential fishing zones (PFZ) along the coast of North Tamil Nadu, India. Indian J. Geo-Mar. Sci., 42, 283-292, http://nopr.niscair.res .in/handle/123456789/19657.

Nash, J. D., E. Kunze, J. M. Toole, and R. W. Schmitt, 2004: Internal tide reflection and turbulent mixing on the continental slope. J. Phys. Oceanogr., 34, 
1117-1134, https://doi.org/10.1175/1520-0485(2004)034<1117:ITRATM>2 .0.CO;2.

Nayak S., T. S. Kumar, and M. N. Kumar, 2007: Satellite based fishery service in India. The Full Picture, Group on Earth Observations, 256-257.

Ott, E., and Coauthors, 2004:A local ensemble Kalman filter for atmospheric data assimilation. Tellus, 56A, 415-428, https://doi.org/10.3402/tellusa.v56i5.14462.

Papa, F., S. K. Bala, R. K. Pandey, F. Durand, V. V. Gopalakrishna, A. Rahman, and W. B. Rossow, 2012: Ganga-Brahmaputra River discharge from Jason-2 radar altimetry: An update to the long-term satellite-derived estimates of continental freshwater forcing flux into the Bay of Bengal. J. Geophys. Res., 117, C11021, https://doi.org/10.1029/2012JC008158.

Pingree, R. D., G. T. Mardell, and A. L. New, 1986: Propagation of internal tides from the upper slopes of the Bay of Biscay. Nature, 321, 154-158, https://doi .org/10.1038/321154a0.

Potemra, J. T., M. E. Luther, and J. J. O'Brien, 1991: The seasonal circulation of the upper ocean in the Bay of Bengal. J. Geophys. Res., 96, 12 667-12 683, https:// doi.org/10.1029/91JC01045.

Prasad, V. S., C. J. Johny, and J. S. Sodhi, 2016: Impact of 3D Var GSI-ENKF hybrid data assimilation system. J. Earth Syst. Sci., 125, 1509-1521, https://doi .org/10.1007/s12040-016-0761-3.

Rao, S. A., and Coauthors, 2019: Monsoon mission: A targeted activity to improve monsoon prediction across scales. Bull. Amer. Meteor. Soc., 100, 2509-2532, https://doi.org/10.1175/BAMS-D-17-0330.1.

Ravichandran, M., D. Behringer, S. Sivareddy, M. S. Girishkumar, N. Chacko, and R. Harikumar, 2013: Evaluation of the global ocean data assimilation system at INCOIS: The tropical Indian Ocean. Ocean Modell., 69, 123-135, https://doi .org/10.1016/j.ocemod.2013.05.003.

Sanikommu, S., D. S. Banerjee, B. Baduru, B. Paul, A. Paul, K. Chakraborty, and I. Hoteit, 2019: Impact of dynamical representational errors on an Indian Ocean ensemble data assimilation system. Quart. J. Roy. Meteor. Soc., 145, 36803691, https://doi.org/10.1002/qj.3649.

Sarma, V. V. S. S., and Coauthors, 2018: Ecosystem response in temperature fronts in the northeastern Arabian Sea. Prog. Oceanogr., 165, 317-331, https://doi .org/10.1016/j.pocean.2018.02.004.

Shankar, D., J. P. McCreary, W. Han, and S. R. Shetye, 1996: Dynamics of the East India Coastal Current 1. Analytic solutions forced by interior Ekman pumping and local alongshore winds. J. Geophys. Res., 101, 13975-13991, https://doi .org/10.1029/96JC00559.

— P. N. Vinayachandran, and A. S. Unnikrishnan, 2002: The monsoon currents in the north Indian Ocean. Prog. Oceanogr., 52, 63-120, https://doi .org/10.1016/S0079-6611(02)00024-1.

Sharples, J., C. M. Moore, A. E. Hickman, P. M. Holligan, J. F. Tweddle, M. R. Palmer, and J. H. Simpson, 2009: Internal tidal mixing as a control on continental margin ecosystems. Geophys. Res. Lett., 36, L23603, https://doi.org/10.1029 /2009GL040683.

Shchepetkin, A. F., and J. C. McWilliams, 2005: The Regional Ocean Modeling System (ROMS): A split-explicit, free-surface, topography-following-coordinate oceanic model. Ocean Modell., 9, 347-404, https://doi.org/10.1016/j.ocemod .2004.08.002.

Shenoi, S. S. C., P. K. Saji, and A. M. Almeida, 1999: Near-surface circulation and kinetic energy in the tropical Indian Ocean derived from Lagrangian drifters. J. Mar. Res., 57, 885-907, https://doi.org/10.1357/002224099321514088.

Shetye, S. R., and Vijith, V., 2013: Sub-tidal water-level oscillations in the Mandovi estuary, west coast of India. Estuarine, Coastal Shelf Sci., 134, 1-10.

— A. D. Gouveia, S. S. C. Shenoi, D. Sundar, G. S. Michael, A. M. Almeida, and K. Santanam, 1990: Hydrography and circulation off the west coast of India during the southwest monsoon 1987. J. Mar. Res., 48, 359-378, https://doi .org/10.1357/002224090784988809.

- S. Shenoi, A. Gouveia, G. Michael, D. Sundar, and G. Nampoothiri, 1991: Wind driven coastal upwelling along the western boundary of the Bay of
Bengal during the southwest monsoon. Cont. Shelf Res., 11, 1397-1408, https://doi.org/10.1016/0278-4343(91)90042-5.

_ A. D. Gouveia, S. S. C. Shenoi, D. Sundar, G. S. Michael, and G. Nampoothiri, 1993: The western boundary current of the seasonal subtropical gyre in the Bay of Bengal. J. Geophys. Res., 98, 945-954, https://doi.org/10.1029 $192 \mathrm{JC} 02070$

Sindhu, B., and A. S. Unnikrishnan, 2013: Characteristics of tides in the Bay of Bengal. Mar. Geod., 36, 377-407, https://doi.org/10.1080/01490419.2013. 781088.

_- I. Suresh, A. S. Unnikrishnan, N. Bhatkar, S. Neetu, and G. Michae, 2007: Improved bathymetric datasets for the shallow water regions in the Indian Ocean. J. Earth Syst. Sci., 116, 261-274, https://doi.org/10.1007/s12040-007 -0025-3.

Solanki, H. U., R. M. Dwivedi, S. R. Nayak, J. V. Jadeja, D. B. Thaker, H. B. Dave, and M. I. Patel, 2001a: Application of ocean colour monitor chlorophyll and AVHRR SST for fishery forecast: Preliminary validation result off Gujarat coast, northwest coast of India. Indian J. Geo-Mar. Sci., 30, 132-138.

$\longrightarrow, \ldots$, and _ $ـ 2001 \mathrm{~b}$ : Synergistic analysis of SeaWiFS chlorophyll concentration and NOAA-AVHRR SST features for exploring marine living resources. Int. J. Remote Sens., 22, 3877-3882, https://doi.org/10.1080 101431160110069845.

_ _ _ _ V. S. Somvanshi, D. K. Gulati, and S. K. Pattnayak, 2003: Fishery forecast using OCM chlorophyll concentration and AVHRR SST: Validation results off Gujarat coast, India. Int. J. Remote Sens., 24, 3691-3699, https://doi .org/10.1080/0143116031000117029.

_ P. C. Mankodi, S. R. Nayak, and V. S. Somvanshi, 2005: Evaluation of remotesensing-based potential fishing zones (PFZs) forecast methodology. Cont. Shelf Res., 25, 2163-2173, https://doi.org/10.1016/j.csr.2005.08.025.

Song, Y., and D. B. Haidvogel, 1994: A semi-implicit ocean circulation model using a generalized topography-following coordinate system. J. Comput. Phys., 115, 228-244, https://doi.org/10.1006/jcph.1994.1189.

Subeesh, M. P., 2019: Tidal currents on the continental shelf and slope off the west coast of India. Ph.D. thesis, Goa University, 181 pp.

_- A. Unnikrishnan, V. Fernando, Y. Agarwadekar, S. Khalap, N. Satelkar, and S. S. C. Shenoi, 2013: Observed tidal currents on the continental shelf off the west coast of India. Cont. Shelf Res., 69, 123-140, https://doi.org/10.1016/j .csr.2013.09.008.

Sumit Kumar, A., and Coauthors, 2018: Implementation of new high resolution NCUM analysis-forecast system in Mihir HPCS. NCMRWF Tech. Rep. NMRF/ TR/01/2018, 17 pp.

Tonani, M., and Coauthors, 2015: Status and future of global and regional ocean prediction systems. J. Oper. Oceanogr., 8, s201-s220, https://doi.org/10.1080 /1755876X.2015.1049892.

Unnikrishnan, A. S., S. R. Shetye, and G. S. Michael, 1999: Tidal propagation in the Gulf of Khambhat, Bombay high, and surrounding areas. Proc. Indian Acad. Sci., 108, 155-177, https://doi.org/10.1007/BF02842329.

Vinayachandran, P. N., and J. Kurian, 2007: Hydrographic observations and model simulation of the Bay of Bengal freshwater plume. Deep-Sea Res. I, 54, $471-$ 486, https://doi.org/10.1016/j.dsr.2007.01.007.

Wang, X., and C. H. Bishop, 2003: A comparison of breeding and ensemble transform Kalman filter ensemble forecast schemes. J. Atmos. Sci., 60, 1140-1158, https://doi.org/10.1175/1520-0469(2003)060<1140:ACOBAE >2.0.C0;2.

Waterhouse, A. F., and Coauthors, 2014: Global patterns of diapycnal mixing from measurements of the turbulent dissipation rate. J. Phys. Oceanogr., 44, 1854-1872, https://doi.org/10.1175/JPO-D-13-0104.1.

Wolf-Gladrow, D. A., 2001: $\mathrm{CO}_{2}$ in Seawater: Equilibrium, Kinetics, Isotopes. Elsevier, $360 \mathrm{pp}$.

Yu, L., J. J. O'Brien, and J. Yang, 1991: On the remote forcing of the circulation in the Bay of Bengal. J. Geophys. Res., 96, 20449, https://doi.org/10.1029 $191 \mathrm{JC} 02424$. 